\title{
Thinking Styles and Cognitive Development
}

\author{
LI-FANG ZHANG \\ Department of Education \\ The University of Hong Kong
}

\begin{abstract}
Using R. J. Sternberg's $(1988,1997)$ theory of thinking styles and W. G. Perry's (1970) theory of cognitive development, the author investigated the nature of thinking styles as they relate to cognitive development. Eighty-two Hong Kong university students (44 male, 38 female) responded to the Thinking Styles Inventory (R. J. Sternberg \& R. K. Wagner, 1992) and the Zhang Cognitive Development Inventory (L. F. Zhang, 1997). Statistical analyses provided varying degrees of support for the prediction of an overlap between the thinking style and cognitive development constructs. In general, students who reasoned at a higher cognitive developmental level tended to use a wider range of thinking styles than students who reasoned at a lower cognitive developmental level. Implications of results are discussed in relation to education and research.
\end{abstract}

Key words: cognitive development, thinking styles

STYLES, AS AN INDIVIDUAL-DIFFERENCE VARIABLE in human performance, have attracted the attention of many scholars and educational psychologists. In the study of styles, many different labels with the root word style have been created. The three most frequently used terms are cognitive styles, learning styles, and thinking styles. Although the three types of styles are conceptually different (see Sternberg \& Zhang, 2001b), they are similar in one important way. That is, they are all different from abilities. An ability refers to what one can do, whereas a style refers to how one prefers to use one's abilities. Major research on and theorization of styles have been summarized in a few recent works (e.g., Jonassen \& Grabowski, 1993; Riding \& Cheema, 1991; Riding \& Rayner, 1998; Sternberg \& Zhang, 2001a).

As one of the latest theories of styles, Sternberg's $(1988,1997)$ theory of mental self-government, a theory of thinking styles, is drawing increasing inter-

The author is grateful for the support of the Wu Jieh-Yee Research Fund, administered by The University of Hong Kong, and expresses special thanks to Mark Mason for his great help with data collection.

Address correspondence to Li-fang Zhang, Department of Education, The University of Hong Kong, Pokfulam Road, Hong Kong; lfzhang@hkucc.hku.hk (e-mail). 
est among scholars. Using government as a metaphor, Sternberg argued that just as there are many ways of governing a society, people have many ways of managing or governing their activities, and they do so in a style with which they feel comfortable. In addition, people's thinking styles vary depending on the stylistic demands of a given situation and are at least partially socialized, suggesting that they can be modified. Sternberg's theory describes 13 thinking styles that fall within the following five dimensions of mental self-government: functions (legislative, executive, and judicial styles), forms (hierarchic, oligarchic, monarchic, and anarchic styles), levels (global and local styles), scopes (internal and external styles), and leanings (liberal and conservative styles). See the Appendix for a brief description of each of the 13 styles.

Although styles are popularly viewed as being value free, some scholars contend that they have never been so. Kogan (1989), for example, has supported the latter argument with convincing examples. He pointed out, regarding Witkin's notion of field dependence/independence, that all training studies have tried to make individuals more field independent rather than more field dependent. He further noted that similar considerations hold even more strongly in the case of a reflection-impulsivity style, for which all training efforts have been directed at the enhancement of the reflective style and for which positive characteristics associated with an impulsive style have yet to be demonstrated.

In the case of the theory of mental self-government, the value accompanying most of the styles can be easily detected. Some styles (e.g., legislative, judicial, hierarchic, global, and liberal; hereafter referred to as Type I thinking styles) are more creativity generating and require more cognitive complexity. Some other styles (e.g., executive, local, monarchic, and conservative; hereafter referred to as Type II thinking styles) are more norm favoring and require more simplistic information processing. The internal and external styles seem to be relatively neutral.

The theory of mental self-government has been operationalized through a few inventories, including the Thinking Styles Inventory (Sternberg \& Wagner, 1992) and the Thinking Styles in Teaching Inventory (Grigorenko \& Sternberg, 1993). Research has been conducted that has demonstrated both the internal and external validity as well as the reliability of these inventories. The usefulness of the two inventories has also been assessed in educational settings in such cultures as the United States, Hong Kong, mainland China, and the Philippines.

Research on thinking styles within an educational context has yielded several findings. First, students' thinking styles vary as a function of their personal characteristics and their learning environment. Second, the thinking styles of teachers, as manifested in teaching, differ depending on their personal characteristics, their teaching experiences, and the school environment. Third, students tend to achieve better academic results when their thinking styles match the thinking styles of their teachers. Finally, students' thinking styles contribute to their academic achievement beyond what can be explained by their abilities, as 
assessed by both self-rating and performance tests (for details, see Grigorenko \& Sternberg, 1997; Sternberg \& Grigorenko, 1995; Zhang, 1999b, 2001a, 2001b; Zhang \& Sternberg, 1998).

Researchers have examined the nature of thinking styles described in the theory of mental self-government by testing the thinking styles against a number of constructs that are believed to be associated with the thinking style construct. For example, studies have been conducted to examine the relationships of thinking styles to (a) learning approaches, as proposed by Biggs (1987, 1992); (b) personality types, as proposed by Holland (1973, 1994); and (c) self-esteem, as measured by the Self-Esteem Inventory-Adult Form (Coopersmith, 1981). A brief summary of the findings of that research follows.

First, students rated as high in Type I thinking styles tend to take a deep approach to learning, whereas students rated high in Type II thinking styles tend to take a surface approach (Zhang, 2000b; Zhang \& Sternberg, 2000). Second, factor analysis of the thinking styles defined in Sternberg's theory and the six personality types defined in Holland's theory resulted in two factors that each contained certain thinking styles and certain personality types, suggesting an overlap between the two constructs. One of the factors was loaded with scales that indicate that people approach the outer world by interacting with others and by evaluating different ideas and situations but not by working alone. The other factor was loaded with scales that suggest that people prefer carrying out detailed and routine tasks with given instructions and dislike working under unstructured situations (Zhang, 2000a). Third, in a study of university students, Zhang (2001c) found that students who preferred to use Type I thinking styles appeared to have significantly higher self-esteem than students who preferred to use Type II thinking styles.

In this study, I focused on thinking styles as postulated in the theory of mental self-government with the intention of facilitating an understanding of the nature of thinking styles and addressing a fundamental, yet unanswered, question: What is the relationship of thinking styles to cognitive development? At heart, the present research was an attempt to connect the cognitive developmental approach and the individual differences (or styles) approach to the study of human psychology.

The importance of interconnecting the cognitive developmental and individual differences approaches cannot be overemphasized. Both cognitive development and individual differences play an important role in human performance. Therefore, the study of either of the two constructs is invaluable to the understanding and enhancement of human performance. However, as stated by Globerson and Zelniker (1989b), "the incorporation of the developmental and individual differences approaches would be essential in order to better understand both cognitive development and individual variability" (p. 1).

According to De Ribaupierre (1989), early efforts to study the relationship between cognitive development and individual differences began around the late 1950 s and early 1960s. Cronbach's (1957) recommendations for bringing togeth- 
er developmental and differential psychology were not followed for many years in North America (Resnick, 1976; Sternberg, 1981). In France, Reuchlin (1962) is known as the first scholar to advocate an integration of the two approaches, and his work was followed by some empirical studies (e.g., Longeot, 1969). However, it was the pioneering work of Pascual-Leone (1969) in the integration of Piaget's (1952) and Witkin's (1962) approaches that propelled further empirical research in the 1970s and early 1980s (e.g., Brodzinsky, 1982; Case, 1974, 1975; Case \& Globerson, 1974; Case \& Pascual-Leone, 1975; Linn, 1978). With the publication of Globerson and Zelniker's (1989a) book Cognitive Style and Cognitive Development, the literature on the relationship between developmental and individual differences approaches reached its peak. Since then, little related work has been documented. A thorough search of this topic in the PsycINFO database (known as the PsycLit until recently) resulted in two entries after the year 1989 (Solís-Cámara, 1996; Westreich, Ritzler, \& Duncan, 1997). The majority of empirical studies cited found significant relationships between cognitive development and cognitive styles.

Thus, despite its importance, the relationship between the cognitive developmental approach and the individual differences approach has not been given enough attention in the last decade or so. At least three major limitations in previous research indicate the need to continue the dialogue between the two disciplines. First, nearly all previous studies were performed on the basis of Witkin's (1962) field dependence/independence style model, which has been criticized for not actually measuring cognitive style (e.g., Guilford, 1970; Kagan, 1965). Other scholars (e.g., Flexer \& Roberge, 1980; Goldstein \& Blackman, 1978; Kush, 1996) have suggested that the field dependence/independence dimension may measure some component of cognitive ability (also, see Armstrong, 2000). Second, virtually all existing research on the relationship between cognitive development and cognitive styles was conducted with very young school children. Third, no similar research has been conducted in east Asia. In this study, I attempted to overcome those limitations by (a) conducting this research on the basis of two more recent theoretical frameworks and (b) involving university students in Hong Kong as participants.

For the theoretical framework of styles, as stated previously, I used Sternberg's theory of mental self-government. For the theoretical framework of cognitive development, I used Perry's $(1970,1981)$ theory of intellectual development, a theory specially constructed for understanding the cognitive development of university students.

Adopting an epistemological approach pioneered by Piaget (1952), Perry $(1970,1981)$ constructed a theory that is aimed at tracing the development of ways of reasoning among American university students. Perry's theory consists of nine positions and delineates the steps through which students develop from being dualistic and concrete, to being more contingent and relativistic, and then to being more committed. Because some of the adjacent positions are similar, 
Perry placed the nine positions in three sequential categories: dualism, relativism, and commitment (also, see Richardson, 1987).

Similar to Piaget's (1952) theory of cognitive development, Perry's (1970, 1981) theory focuses on how students think but not what they think. Perry argued that a student's form of reasoning transcends content. In this study, I dealt with two content areas: education and interpersonal relationships (see the Method section for details).

Research and application of Perry's $(1970,1981)$ theory have been well documented in the literature. Researchers have shown that, in general, Perry's theory is valid and that cognitive development as described in the theory plays an important role in students' academic performance (e.g., Ryan, 1984a, 1984b; Schommer, 1990, 1993; Schommer, Calvert, Gariglietti, \& Bajaj, 1997; Schommer, Crouse, \& Rhodes, 1992). Furthermore, researchers of cross-cultural studies (e.g., Durham, Hays, \& Martinez, 1994; Zhang, 1999a) have also suggested the validity of Perry's theory, although cross-cultural differences were identified in these studies, as would be expected, given that cultural factors have been proven to have a strong impact on cognitive development (e.g., Mwamwenda, 1992; Rogoff \& Chavajay, 1995; Slone, Dixon, \& Bokhorst, 1993).

Unlike Piaget's (1952) theory, however, Perry's $(1970,1981)$ theory of cognitive development has not been tested against a theoretical model that takes an individual differences approach, such as Sternberg's $(1988,1997)$ theory of mental selfgovernment. In this study, I examined whether the sequential categories of cognitive development described by Perry could be predicted by the thinking styles in Sternberg's theory. Overall, I was concerned with two of Perry's sequential categories, the dualistic and relativistic levels of cognitive development. I did not assess commitment because very few undergraduate students attain high levels of commitment (see Knefelkamp, 1974; Widick, Knefelkamp, \& Parker, 1975), and the research participants in this study were in their second year of university education.

I anticipated that thinking styles would statistically predict cognitive developmental levels. Specifically, I expected that Type I thinking styles (legislative, judicial, hierarchic, global, and liberal) would be significantly related to relativism, whereas Type II thinking styles (executive, local, monarchic, and conservative) would be significantly related to dualism. Furthermore, I expected that relativism would be related to the use of a wider repertoire of thinking styles and that dualism would be related to the use of a relatively narrower repertoire of thinking styles.

The characteristics of the different thinking styles and the characteristics of the dualistic and relativistic levels of cognitive development served as the basis for the first prediction. For example, carrying out tasks in a more creative, analytical, and nontraditional way and at a more abstract level (i.e., using Type I thinking styles) would require students to reason with a critical mind (i.e., being relativistic). In contrast, focusing on one concrete task in a traditional way with clear instructions (i.e., using Type II thinking styles) would require one to think 
in only absolute, right-wrong and black-white, terms (i.e., being dualistic). I made the second prediction on the basis of one of the three "unusual features" (King, 1978) of Perry's $(1970,1981)$ theory. That is, in contrast to other developmental theories, Perry's theory provides three alternatives to forward progression. One of those alternatives is retreat, in which a student returns to a dualistic orientation to find security and the strength to cope with an overchallenging environment. I expected that students who scored significantly higher on the relativism scale would use Type I thinking styles as their primary way of dealing with tasks; yet, at times, certain overchallenging tasks might force these students to resort to Type II and neutral thinking styles. The relativists, therefore, should have been able to traverse different types of styles. However, the dualists should have found comfort only in using Type II thinking styles.

\section{Method}

\section{Participants}

Eighty-two (44 male and 38 female) 2nd-year students from the University of Hong Kong volunteered to participate in this research. These participants were enrolled in an elective course on critical thinking, which can be taken by any 2ndyear student from the participating university. The average age of students was 20 years $(S D=0.99$; range $=19$ to 26 years $)$, and they were from such study areas as architecture, arts, education, engineering, law, science, and social sciences. Sixty-six percent of the participants did not have any work experience, and the remaining participants reported either part- or full-time work experience.

\section{Measures}

All research participants responded to the Thinking Styles Inventory (TSI; Sternberg \& Wagner, 1992) and the Zhang Cognitive Development Inventory (ZCDI; Zhang, 1997). Furthermore, they responded to a demographic questionnaire that elicited such information as the participants' age, gender, and work experience.

The TSI is a self-report test consisting of 65 statements. Each of the 13 thinking styles described in the theory of mental self-government is assessed by 5 of these statements. For each statement, the participants rated themselves on a 7point Likert-type scale, with 1 indicating that the statement does not at all describe the way they normally carry out tasks and 7 denoting that the statement characterizes extremely well the way they normally carry out tasks. In this study, the participants responded to a Chinese version of the inventory that was translated and back translated between Chinese and English in 1996. Because I did not anticipate a significant relationship between the oligarchic and anarchic styles and any of the Perry cognitive development levels under investigation, I omitted these two styles from the present study. 
As discussed, the TSI has demonstrated good reliability in previous studies. The Cronbach alpha coefficients have ranged from the mid .50s to the low .80s, with the majority being in the mid .70s. In this study, the Cronbach alpha coefficients were $.74, .75, .75, .72, .50, .79, .77, .82, .63, .79$, and .67 for the legislative, executive, judicial, global, local, liberal, conservative, internal, external, hierarchic, and monarchic thinking styles, respectively. Also, as mentioned before, the TSI has shown both internal and external validity.

The ZCDI (fourth version), also a self-report test, is composed of 75 statements that assess three levels of cognitive development (dualism, relativism, and commitment), as defined in Perry's theory $(1970,1981)$. Because commitment is not considered significantly relevant to 2nd-year university students, I used only items in the dualism and relativism scales in the present research. Both the dualism and relativism items span two content areas: education and interpersonal relationships. An education item assesses the participants' way of reasoning in learning situations. An interpersonal relationship item assesses the participants' way of reasoning in social situations. The test items are contained in four subscales: education/dualism (ED), education/relativism (ER), interpersonal relationship/ dualism (ID), and interpersonal relationship/relativism (IR). For each item, the respondents rated themselves on a 7-point Likert-type scale anchored by 1 , denoting that the respondent absolutely disagrees with the statement, and 7, denoting that the respondent absolutely agrees.

The history of the development of the ZCDI as well as its reliability and validity data can be found in Zhang's earlier work (e.g., Zhang, 1995, 1999a; Zhang \& Hood, 1998). In a previous study using the same version of the ZCDI, Zhang and Watkins (2001) obtained the following alpha coefficients: .74 (ED), .64 (ER), .65 (ID), and .56 (IR) for an American sample and .70 (ED), .57 (ER), .72 (ID), and .62 (IR) for a Chinese sample. The alpha coefficients for the overall scales were .82 and .73 for the dualism and relativism scales, respectively, for the American sample and .81 and .68 for the dualism and relativism scales, respectively, for the Chinese sample. The validity of the scales was suggested by the interscale correlations, which were in the predicted directions.

In the present study, the Cronbach alpha coefficients for the subscales were $.80, .72, .77$, and .61 for ED, ER, ID, and IR, respectively. The alpha coefficients for the overall scales were .87 for dualism and .79 for relativism.

\section{Data Analysis}

Previous researchers have found that both thinking styles (e.g., Sternberg \& Grigorenko, 1995; Zhang, 1999b) and cognitive development (e.g., Belenky, Clinchy, Goldberger, \& Tarule, 1986; Zhang, 1999a) can be affected by age, gender, and previous experiences. In this study, I conducted preliminary statistical analyses to identify possible differences in thinking styles and cognitive development based on age, gender, and previous work experience. No sta- 
tistically significant difference was found for any of the three variables. To examine the relationships between thinking styles and cognitive development, I used three statistical procedures. First, a zero-order correlation matrix was computed, with the thinking styles scales as one set of variables and the overall dualism and relativism scales as another. Second, the 11 thinking styles and the four ZCDI subscales were submitted to factor analyses. Third, stepwise multiple regression analyses were conducted with thinking styles as the independent variables and the overall dualism and relativism scores as the dependent variables.

\section{Results}

\section{Scale Correlations Between the TSI and ZCDI}

Pearson's correlations among the scales from the two inventories largely supported the first prediction and fully supported the second prediction. First, with the exception of the internal thinking style (a neutral style) being significantly correlated with the dualism scale, the remaining thinking styles that were significantly related to the dualism scale were all Type II styles. Second, precisely as expected, all Type I thinking styles were significantly related to the relativism scale. In addition, two of the Type II thinking styles (local and monarchic styles) as well as two relatively neutral styles (internal and external) were also significantly correlated with the relativism scale. The correlation coefficients among the scales of the two inventories are presented in Table 1.

\section{Principal Component Factor Analysis: A Two-Factor Model}

According to the two predictions, I expected a two-factor model to result from a principal component factor analysis. The first factor should have contained Type I styles and the relativism subscales, and the second factor should have contained Type II styles and the dualism subscales, with the neutral thinking styles being clustered with the former. Therefore, a two-factor model was specified in the initial factor analysis. Like the results from the zero-order correlation matrix, the results from this factor analysis lent full support to the second prediction, whereas the first prediction was strongly, although not fully, supported by the data. The first factor was dominated by the two relativism subscales (education/relativism and interpersonal relationship/relativism) as well as by all of the Type I thinking styles. In addition, the local and monarchic thinking styles showed high factor loadings for Factor 1. Factor 2 was dominated by the two dualism subscales (education/dualism and interpersonal relationship/dualism) as well as by three of the four Type II thinking styles (executive, conservative, and local). Contrary to expectation, the monarchic scale did not load on Factor 2. Detailed statistics of this analysis are presented in Table 2 . 
TABLE 1

Zero-Order Correlation Coefficients: Thinking Styles and Cognitive Developmental Levels $(N=82)$

\begin{tabular}{lcc}
\hline \hline Scale & Dualism & Relativism \\
\hline Legislative & .08 & $.37^{* *}$ \\
Executive & $.38^{* *}$ & .12 \\
Judicial & .02 & $.56^{* *}$ \\
Global & .15 & $.26^{*}$ \\
Local & $.26^{*}$ & $.23^{*}$ \\
Liberal & -.07 & $.47^{* *}$ \\
Conservative & $.36^{* *}$ & .08 \\
Internal & $.29^{*}$ & $.29^{*}$ \\
External & -.10 & $.32^{* *}$ \\
Hierarchical & .21 & $.28^{*}$ \\
Monarchical & $.26^{*}$ & $.35^{* *}$ \\
& & \\
\hline
\end{tabular}

$* p<.05 . * * p<.01$

TABLE 2

Factor Loadings: Two-Factor Model $(N=82)$

\begin{tabular}{lrr}
\hline \hline Scale & Factor 1 & Factor 2 \\
\hline Education/dualism & & .68 \\
Education/relativism & .70 & \\
Interpersonal relationship/dualism & & .67 \\
Interpersonal relationship/relativism & .64 & \\
Legislative & .71 & \\
Executive & & .80 \\
Judicial & .86 & \\
Global & .48 & \\
Local & .48 & .42 \\
Liberal & .86 & -.31 \\
Conservative & & .81 \\
Internal & .54 & .38 \\
External & .38 & \\
Hierarchical & .46 & .40 \\
Monarchical & .56 & \\
\% variance & 34.61 & 15.89 \\
Cumulative variance & 34.61 & 50.50 \\
Eigenvalue & 5.19 & 2.38 \\
\hline
\end{tabular}

Note. Scales with factor loadings of less than $|.30|$ are omitted. 
These two factors, however, accounted for only $50 \%$ of the variance in the data. Indeed, the eigenvalues indicated that the scales from the two inventories clustered in four factors. Therefore, I conducted a principal component analysis that specified an eigenvalue greater than 1 .

\section{Principal Component Factor Analysis: A Four-Factor Model}

Exploratory principal component analysis of the scales from the two inventories yielded four principal components with eigenvalues greater than 1 . Together, the four factors accounted for $69 \%$ of the variance in the data. However, the results from this analysis provided only marginal support for the predictions. Only Factor 4, dominated by high loadings of the two relativism subscales and the judicial and external styles, suggested a relationship between thinking styles and cognitive development. Each of the first three factors was dominated by either the TSI scales or the ZCDI subscales. The first factor was dominated by Type I thinking styles as well as by two of the Type II styles. Factor 2 showed high loadings from the two dualism subscales. Finally, Factor 3 was dominated by Type II styles as well as the external style. Detailed statistics of this analysis are summarized in Table 3.

TABLE 3

Factor Loadings: Four-Factor Model $(N=82)$

Scale

Factor $1 \quad$ Factor $2 \quad$ Factor $3 \quad$ Factor 4

Education/dualism

Education/relativism

Interpersonal relationship/dualism

.82

Interpersonal relationship/relativism

Legislative

.75

Executive

Judicial

Global

Local

Liberal

.67

Conservative

Internal

.90

External

Hierarchical

Monarchical

.67

.62

$\%$ variance

34.61

Cumulative variance 


\section{Stepwise Multiple Regressions}

Stepwise multiple regressions were conducted, with the dualism and relativism scales as the dependent variables and the thinking styles scales as the independent variables. Results indicated that the executive and external thinking styles statistically predicted dualism scores. The two styles accounted for $19 \%$ of the variance in the data, $F(1,73)=12.16, p=.001$. The executive style positively contributed to the dualism score $\left(R^{2}=.14 ; \beta=.45\right)$, whereas the external style negatively contributed to the dualism score $\left(R^{2}=.05 ; \beta=-.23\right)$. As for the statistical prediction of the relativistic cognitive developmental level, only the judicial thinking style entered the regression model. The judicial style accounted for $33 \%$ of the variance in the data, $F(1,74)=35.56, p=.000$ $(\beta=.57)$.

\section{Discussion}

My primary objective in this research was to examine the nature of thinking styles by exploring their relationship to cognitive development. Results from the correlation matrix and a preliminary factor analysis lent strong support to the two predictions: Students who were at Perry's $(1970,1981)$ dualistic level of cognitive development tended to use a narrower repertoire of thinking styles that are more norm favoring and require more simplistic information processing. In contrast, students who were at Perry's relativistic level of cognitive development tended to use a wider repertoire of thinking styles, including Type II and neutral styles, apart from Type I styles. This result not only supported the predictions but also provided empirical evidence for Perry's theoretical argument about students' retreat to the dualistic way of reasoning (also, see Westreich et al., 1997). In this context, students at the relativistic level of reasoning may resort to less challenging styles, such as the local and monarchic styles.

Yet, a careful cross-examination of the results from the correlation matrix and the two-factor model reveals that the relativists would make their retreat using the local and monarchic styles, but they would not resort to the executive and conservative styles. Given this finding, it seems fair to say that using the executive and conservative thinking styles might imply a certain cognitive developmental immaturity. Moreover, only the dualists tended to use these two styles (executive and conservative) frequently.

These findings, although providing support for the predictions and confirming results of previous studies based on other theoretical frameworks (e.g., Case, 1975; Case \& Globerson, 1974; Solís-Cámara, 1996), must be qualified. A twofactor model was specified so I could examine the predictions about the relationships between thinking styles and cognitive development. However, only $50 \%$ of the variance in the data was accounted for by the two factors. Thus, I introduced a factor analysis that allowed for a clearer picture of the scale clusters. That 
is, a factor analysis was conducted that allowed all factors with eigenvalues greater than 1 to be in the model.

Results from this factor analysis indicated that the relationship between thinking styles and cognitive development is manifested by only two thinking styles (judicial and external) and one level of cognitive development (relativism). This relationship makes substantive sense. The judicial style is characterized by critical evaluation of ideas, people, and other people's work. The external style is characterized by a preference for working with other people. Thus, the use of the judicial and external thinking styles necessarily engages an individual in relativistic reasoning. This reasoning is consistent with the Piagetian account of how cognitive development occurs. Piaget (1952) believed that cognitive development occurs when an individual is confronted with and works through cognitive conflicts. In the context of Sternberg's $(1988,1997)$ and Perry's $(1970,1981)$ theories, those who prefer to use the judicial and external styles would necessarily put themselves in situations in which they would need to work through cognitive conflicts. Thus, they demonstrate the relativistic way of reasoning according to the Perry scheme. This explanation, however, seems to cast thinking styles and cognitive development in a causal relationship. Of course, because this study was not experimental in nature, no causal relationship should be assumed. Yet, in a statistical sense, a causal relationship was tested. That is, multiple regression analyses were conducted to find out if thinking styles significantly contributed to cognitive development.

Results from the regression analyses provided additional information to what had been revealed by the four-factor model. Apart from confirming that the judicial style statistically contributed to the relativism scale, regression analyses results indicated that the executive thinking style statistically contributed to the dualism scale. Furthermore, instead of indicating a positive relationship between the external thinking style and the relativism scale, as did the four-factor model, results from regression analyses suggested that the use of the external thinking style significantly negatively contributed to the dualistic way of reasoning. Again, these results make substantive sense (as did the relationship between judicial style and relativism, as has been explained). The executive thinking style is characterized by one's following clear guidelines in task performance, which is a manifestation of showing absolute respect to authorities (as the dualists do).

\section{Conclusions and Implications}

This study makes two major contributions. First, it adds to the growing body of work relevant to the investigation of the nature of thinking styles postulated in the theory of mental self-government. Second, by providing empirical data, the study facilitates an understanding of the nature of thinking styles as they relate to cognitive developmental levels. Thus, it contributes to the body of 
knowledge concerning the connection between the developmental approach and the individual differences approach, which has been dormant for the last decade or so. The varying degrees of support for the predictions, obtained from different statistical procedures, indicate that the study's findings are suggestive rather than conclusive.

On the basis of the data reported, the following preliminary conclusions appear to be warranted. First, although the thinking style and cognitive development constructs overlap to a degree, the two constructs seem to be very different. Thinking styles are more flexible, and cognitive developmental levels are more stable. Second, students who reason at a higher cognitive developmental level tend to use a larger repertoire of thinking styles than students reasoning at a lower cognitive developmental level who are confined to a narrow range of thinking styles. Finally, this study reveals that the use of the judicial thinking style is the most conducive to cognitive development. In contrast, the use of the executive thinking style is most likely to inhibit growth, according to the Perry theory of cognitive development. In addition, working with others (using the external style) might help individuals resist dualistic reasoning.

These preliminary conclusions imply that educators who are committed to helping students progress along Perry's cognitive developmental scheme, in addition to using other strategies, might also make use of the relationships between thinking styles and cognitive development. Educators may enhance students' cognitive development by encouraging students to engage in a variety of thinking styles in their task performance. These tasks can be, according to the results of the present study, of both an educational and an interpersonal nature. In particular, tasks that require students to think critically and to work with others can promote relativistic reasoning and counteract dualistic reasoning.

As stated previously, however, these conclusions are not based on results from an experimental study. To acquire a better understanding of how thinking styles contribute to cognitive development, one would need to undertake an investigation that involves an experimental component.

\section{REFERENCES}

Armstrong, S. J. (2000). The influence of individual cognitive style on performance in management education. Educational Psychology, 20(3), 323-339.

Belenky, M. F., Clinchy, B. M., Goldberger, N. R., \& Tarule, J. M. (1986). Women's ways of knowing: The development of self, voice, and mind. New York: Basic Books.

Biggs, J. B. (1987). Student approaches to learning and studying. Hawthorn, Victoria: Australian Council for Educational Research.

Biggs, J. B. (1992). Why and how do Hong Kong students learn? Using the Learning and Study Process Questionnaires (Education Paper No. 14). The University of Hong Kong, Faculty of Education.

Brodzinsky, D. M. (1982). Relationship between cognitive style and cognitive development: A 2-year longitudinal study. Developmental Psychology, 18(4), 617-626.

Case, R. (1974). Structures and strictures: Some functional limitations on the course of cognitive growth. Cognitive Psychology, 6, 544-573. 
Case, R. (1975). Gearing the demands of instruction to the developmental capacities of the learner. Review of Educational Research, 45(1), 59-87.

Case, R., \& Globerson, T. (1974). Field independence and central computing space. Child Development, 45, 772-778.

Case, R., \& Pascual-Leone, J. (1975). Failure of conservation training of disadvantaged black teenagers: A neo-Piagetian interpretation. Perceptual and Motor Skills, 40, 545-546.

Coopersmith, S. (1981). Self-esteem inventories. Palo Alto, CA: Consulting Psychologists Press.

Cronbach, L. J. (1957). The two disciplines of scientific psychology. American Psychologist, 12, 671-684.

De Ribaupierre, A. (1989). Cognitive style and operational development: A review of French literature and a neo-Piagetian reinterpretation. In T. Globerson \& T. Zelniker (Eds.), Cognitive style and cognitive development: Vol. 3. Human development (pp. 86-115). Norwood, NJ: Ablex.

Durham, R. L., Hays, J., \& Martinez, R. (1994). Socio-cognitive development among Chicano and Anglo American college students. Journal of College Student Development, $35,178-182$.

Flexer, B. K., \& Roberge, J. J. (1980). IQ, field dependence-independence, and the development of formal operational thought. The Journal of General Psychology, 103, 191-201.

Globerson, T., \& Zelniker, T. (Eds.). (1989a). Cognitive style and cognitive development: Vol. 3. Human development. Norwood, NJ: Ablex.

Globerson, T., \& Zelniker, T. (1989b). Introduction. In T. Globerson \& T. Zelniker (Eds.), Cognitive style and cognitive development: Vol. 3. Human development (pp. 1-9). Norwood, NJ: Ablex.

Goldstein, K. M., \& Blackman, S. (1978). Cognitive style: Five approaches and relevant research. New York: Wiley Interscience.

Grigorenko, E. L., \& Sternberg, R. J. (1993). Thinking Styles in Teaching Inventory. Unpublished test, Yale University, New Haven, CT.

Grigorenko, E. L., \& Sternberg, R. J. (1997). Styles of thinking, abilities, and academic performance. Exceptional Children, 63(3), 295-312.

Guilford, J. (1970). The nature of human intelligence. New York: McGraw-Hill.

Holland, J. L. (1973). Making vocational choices: A theory of careers. Englewood Cliffs, NJ: Prentice-Hall.

Holland, J. L. (1994). Self-directed search. Odessa, FL: Psychological Assessment Resources.

Jonassen, D. H., \& Grabowski, B. L. (1993). Handbook of individual differences: Learning and instruction. Hillsdale, NJ: Erlbaum.

Kagan, J. (1965). Individual differences in the resolution of response uncertainty. Journal of Personality and Social Psychology, 2, 154-160.

King, P. M. (1978). William Perry's theory of intellectual and ethical development. In L. Knefelkamp, C. Widick, \& C. A. Parker (Eds.), New directions for student services: Applying new developmental findings (No. 4, pp. 35-51). San Francisco: Jossey-Bass.

Knefelkamp, L. L. (1974). Developmental instruction: Fostering intellectual and personal growth in college students. Dissertation Abstracts International, 36, 1271A. (UMI No. 75-21, 059)

Kogan, N. (1989). A stylistic perspective on metaphor and aesthetic sensitivity in children. In T. Globerson \& T. Zelniker (Eds.), Cognitive style and cognitive development: Vol. 
3. Human development (pp. 192-213). Norwood, NJ: Ablex.

Kush, J. C. (1996). Field dependence, cognitive ability, and academic achievement in Anglo American and Mexican American students. Journal of Cross-Cultural Psychology, 27, 561-575.

Linn, M. C. (1978). Influence of cognitive style and training on tasks requiring the separation of variables schema. Child Development, 49, 874-877.

Longeot, F. (1969). Psychologie différentielle et théorie opératoire de l'intelligence [Differential psychology and operational theory of intelligence]. Paris: Dunod.

Mwamwenda, T. S. (1992). Culture, environment: Value judgments about cognitive development. Psychological Reports, 70, 721-722.

Pascual-Leone, J. (1969). Cognitive development and cognitive style: A general psychological integration. Unpublished doctoral dissertation, University of Geneva, Switzerland.

Perry, W. G. (1970). Forms of intellectual and ethical development in the college years: A scheme. New York: Holt, Rinehart and Winston.

Perry, W. G. (1981). Cognitive and ethical growth: The making of meaning. In A. Chickering (Ed.), The modern American college (pp. 76-116). San Francisco: Jossey-Bass.

Piaget, J. (1952). The origins of intelligence in children. New York: International Universities Press.

Resnick, L. (Ed.). (1976).The nature of intelligence. Hillsdale, NJ: Erlbaum.

Reuchlin, M. (1962). Les méthodes quantitatives en psychologie [Quantitative methods in psychology]. Paris: PUF.

Richardson, J. T. E. (1987). Research in education and cognitive psychology. In J. T. E. Richardson, M. W. Eysenck, \& D. W. Piper (Eds.), Student learning: Research in education and cognitive psychology (pp. 3-12). Milton Keynes, England: SRHE and Open University Press.

Riding, R., \& Cheema, I. (1991). Cognitive styles-An overview and integration. Educational Psychology, 11, 193-215.

Riding, R. J., \& Rayner, S. (1998). Cognitive styles and learning strategies: Understanding style differences in learning and behavior. London: Fulton.

Rogoff, B., \& Chavajay, P. (1995). What's become of research on the cultural basis of cognitive development? American Psychologist, 50(10), 859-877.

Ryan, M. P. (1984a). Conceptions of prose coherence: Individual differences in epistemological standards. Journal of Educational Psychology, 76(6), 1226-1238.

Ryan, M. P. (1984b). Monitoring text comprehension: Individual differences in epistemological standards. Journal of Educational Psychology, 76(2), 249-258.

Schommer, M. (1990). Effects of beliefs about the nature of knowledge on comprehension. Journal of Educational Psychology, 82, 498-504.

Schommer, M. (1993). Epistemological development and academic performance among secondary students. Journal of Educational Psychology, 85(3), 406-411.

Schommer, M., Calvert, C., Gariglietti, G., \& Bajaj, A. (1997). The development of epistemological beliefs among secondary students: A longitudinal study. Journal of Educational Psychology, 89(1), 37-40.

Schommer, M., Crouse, A., \& Rhodes, N. (1992). Epistemological beliefs and mathematical text comprehension: Believing it is simple does not make it so. Journal of Educational Psychology, 82, 435-443.

Slone, M., Dixon, J. A., \& Bokhorst, F. D. (1993). Physical knowledge of sugar water solutions: Cross-cultural data. The Journal of Genetic Psychology, 155(1), 65-75.

Solís-Cámara, P. R. (1996). Random and cognitive responders on the Matching Familiar Figures Test: Alternatives for users. Perceptual and Motor Skills, 85, 543-562. 
Sternberg, R. J. (1981). Testing and cognitive psychology. American Psychologist, 36, 1181-1189.

Sternberg, R. J. (1988). Mental self-government: A theory of intellectual styles and their development. Human Development, 31, 197-224.

Sternberg, R. J. (1997). Thinking styles. New York: Cambridge University Press.

Sternberg, R. J., \& Grigorenko, E. L. (1995). Styles of thinking in the school. European Journal for High Ability, 6, 201-219.

Sternberg, R. J., \& Wagner, R. K. (1992). Thinking Styles Inventory. Unpublished test, Yale University, New Haven, CT.

Sternberg, R. J., \& Zhang, L. F. (Eds.). (2001a). Perspectives on thinking, learning, and cognitive styles. Mahwah, $\mathrm{NJ}$ : Erlbaum.

Sternberg, R. J., \& Zhang, L. F. (2001b). Preface. In R. J. Sternberg \& L. F. Zhang (Eds.), Perspectives on thinking, learning, and cognitive styles (pp. vii-ix). Mahwah, NJ: Erlbaum.

Westreich, A. H., Ritzler, B., \& Duncan, J. (1997). Relationship between cognitive style and defensive style. Perceptual and Motor Skills, 84, 1011-1023.

Widick, C. C., Knefelkamp, L. L., \& Parker, C. A. (1975). The counselor as a developmental instructor. Counselor Education and Supervision, 14, 286-296.

Witkin, H. A. (1962). Psychological differentiation: Studies of development. New York: Wiley.

Zhang, L. F. (1995). The construction of a Chinese language cognitive development inventory and its use in a cross-cultural study of the Perry scheme. Dissertation Abstracts International, 56 (06), 2122A.

Zhang, L. F. (1997). The Zhang Cognitive Development Inventory. Unpublished test, The University of Hong Kong.

Zhang, L. F. (1999a). A comparison of U.S. and Chinese university students' cognitive development: The cross-cultural applicability of Perry's theory. The Journal of Psychology, 133(4), 425-439.

Zhang, L. F. (1999b). Further cross-cultural validation of the theory of mental self-government. The Journal of Psychology, 133(2), 165-181.

Zhang, L. F. (2000a). Are thinking styles and personality types related? Educational Psychology, 20(3), 271-283.

Zhang, L. F. (2000b). Relationship between Thinking Styles Inventory and Study Process Questionnaire. Personality and Individual Differences, 29, 841-856.

Zhang, L. F. (2001a). Approaches and thinking styles in teaching. The Journal of Psychology, 135(5), 547-561.

Zhang, L. F. (2001b). Do styles of thinking matter among Hong Kong secondary school students? Personality and Individual Differences, 31(3), 289-301.

Zhang, L. F. (2001c). Thinking styles, self-esteem, and extracurricular experiences. International Journal of Psychology, 36(2) 100-107.

Zhang, L. F., \& Hood, A. B. (1998). Cognitive development of students in China and the U.S.A.: Opposite directions? Psychological Reports, 82, 1251-1263.

Zhang, L. F., \& Sternberg, R. J. (1998). Thinking styles, abilities, and academic achievement among Hong Kong university students. Educational Research Journal, 13(1), 41-62.

Zhang, L. F., \& Sternberg, R. J. (2000). Are learning approaches and thinking styles related? A study in two Chinese populations. The Journal of Psychology, 134(5), 469-489.

Zhang, L. F., \& Watkins, D. (2001). Cognitive development and student approaches to learning: An investigation of Perry's theory with Chinese and U.S. university students. Higher Education, 41, 239-261. 


\section{APPENDIX \\ Descriptions of Thinking Styles in the Theory of Self-Government}

Thinking style

Description

Legislative

Executive

Judicial

Hierarchic

Monarchic

Oligarchic

Anarchic

Global

Local

Internal

External

Liberal

Conservative
One prefers to work on tasks that require creative strategies; one prefers to choose one's own activities.

One prefers to work on tasks with clear instructions and structures; one prefers to implement tasks with set guidelines.

One prefers to work on tasks that allow for one's evaluation; one prefers to evaluate and judge the performance of other people.

One prefers to distribute attention to several tasks that are ranked in priority according to one's valuing of the tasks.

One prefers to work on tasks that allow complete focus on one thing at a time.

One prefers to work on multiple tasks in the service of multiple objectives without setting priorities.

One prefers to work on tasks that would allow flexibility as to what, where, when, and how one works.

One prefers to pay more attention to the overall picture of an issue and/or to abstract ideas.

One prefers to work on tasks that require working with concrete details.

One prefers to work on tasks that allow one to work as an independent unit.

One prefers to work on tasks that allow for collaborative ventures with other people.

One prefers to work on tasks that involve novelty and ambiguity.

One prefers to work on tasks that allow one to adhere to the existing rules and procedures in performing tasks. 
